\title{
DESVENTURAS DE ALGUNS CRÍTICOS DA POLÍTICA EXTERNA DO GOVERNO LULA
}

Kjeld Aagaard Jakobsen

Se, por um lado, a política externa do governo Lula entre os anos de 2003 e 2010 provocou várias avaliações positivas, nacional e internacionalmente, a ponto de seu ministro das relações exteriores Celso Amorim ser incluído em 2010 entre os cem pensadores globais mais importantes da atualidade pela revista Foreign Affairs, por outro, recebeu críticas contundentes de parte de alguns especialistas brasileiros nesta área.

O objetivo do presente artigo é discutir a consistência de algumas destas críticas apresentadas por intermédio de publicações que vão desde livros a artigos em revistas e jornais. Foram selecionados cinco autores renomados que atuaram ou ainda atuam na diplomacia brasileira, a saber: Celso Lafer, Luiz Felipe Lampreia, Rubens Ricúpero, Paulo Roberto de Almeida e Rubens Barbosa ${ }^{1}$.

\footnotetext{
${ }^{1}$ Celso Lafer foi Ministro das Relações Exteriores de Fernando Collor de Mello (1992) e Fernando Henrique Cardoso (2001 a 2002); Rubens Ricúpero foi Ministro de Meio Ambiente (1993 a 1994) e Ministro da Fazenda de Itamar Franco (Março a Setembro de 1994) e Secretário Geral da UNCTAD (1995 a 2004); Luiz Felipe Lampreia foi Ministro de Relações Exteriores de Fernando Henrique Cardoso (1995 a 2001); Rubens Barbosa foi diplomata de carreira e o último cargo que ocupou foi o de embaixador nos EUA (1999 a 2004) e Paulo Roberto de Almeida é diplomata de carreira e professor universitário.
} 
O conteúdo das críticas destes autores à política externa brasileira (PEB) desenvolvida durante os dois mandatos do presidente Lula varia desde a afirmação de que ela foi "ideologizada e partidarizada", passando por comentários sobre o que consideram equívocos do Itamaraty durante este período, como a busca por uma cadeira permanente no Conselho de Segurança da ONU, encaminhamentos relativos ao Mercosul, insuficiência de resultados no comércio exterior, relações com ditaduras, exacerbação da diplomacia presidencial, entre outras, até chegar a observações como insucessos em candidaturas a cargos em organizações internacionais ou a abertura desnecessária de embaixadas.

No entanto, para balizar a análise deste conjunto de críticas, quatro temas foram selecionados tanto pela abrangência de seu conteúdo como porque as críticas inseridas nestes temas têm ênfase quase comum entre os autores mencionados. Os temas escolhidos são a "ideologização e 276 partidarização" da política externa, a reforma do Conselho de Segurança da ONU, os resultados do comércio exterior e a diplomacia presidencial.

Grosso modo, se vistas de maneira conjunta e articuladas entre si, as críticas seguem uma lógica que parte da afirmação de que a política externa entre 2003 e 2010 impôs uma visão política particular do Partido dos Trabalhadores (PT) nas decisões sobre seus rumos, rompendo o "consenso" construído ao longo de anos de que ela é uma política de Estado e não de governo (Lafer, 2009b). Consequentemente, as autoridades maiores do Itamaraty teriam aderido a essa premissa e as decisões adotadas neste nível se equivocaram e desta forma fizeram com que acordos comerciais importantes não fossem alcançados, assim como a obsessão em conquistar um assento permanente no Conselho de Segurança teria criado mais fricções com outros países do que resultados concretos. Se somar a isso o estilo carismático e ideológico da atuação internacional do Presi- 
dente Lula, que colocou em risco o caráter necessariamente institucional e impessoal da diplomacia (Ricupero, 2010), teríamos um "caldo de insucesso" de grandes proporções.

Analisando as afirmações críticas embutidas nos quatro temas, a percepção é que as divergências fundamentais decorrem de uma análise sistêmica diferenciada e de apreciações quanto ao papel negativo, segundo os autores, exercido pelo Itamaraty e pelo próprio presidente da república na formulação e operacionalização da política externa durante o governo Lula, em comparação com a concepção levada adiante durante os governos pós-regime militar, particularmente nos dois mandatos do presidente Fernando Henrique Cardoso.

Embora críticas a qualquer governo, independentemente de sua origem, sejam legítimas, seria estranho que a política externa do primeiro governo de esquerda da história do Brasil simplesmente seguisse os rumos definidos em governos anteriores aos quais se opôs politicamente. Mesmo assim, apesar de a eleição de Lula representar a vitória de uma coligação política de oposição, sua política externa foi marcada pela continuidade de muitas iniciativas anteriores, algumas inclusive conduzidas pelos críticos em tela, e de ruptura com outras no sentido de buscar novos rumos nas relações internacionais e alargar o horizonte das relações políticas e comerciais.

As relações internacionais do Brasil entre 2003 e 2010, mesmo alterando prioridades definidas por governos anteriores, ampliaram-se quantitativamente e melhoraram qualitativamente sem rompimentos com parceiros tradicionais ou instituições internacionais. O Itamaraty preservou seu insulamento burocrático, bem como o controle da gestão da política externa, e o Ministério de Relações Exteriores inclusive se fortaleceu estruturalmente neste período com a abertura de novas embaixadas, contratação de novos diplomatas, além de contar com forte respaldo presidencial para as suas iniciativas. 


\section{Ideologização e partidarização da PEB}

Os argumentos para afirmar que a política externa teve viés ideológico e partidário durante os mandatos presidenciais de Lula se apoiam em várias afirmações. A começar pela observação de que a concepção internacional do PT seria anti-imperialista e, portanto, antiamericana, bem como "terceiro-mundista" em sua intenção de unir potências do Sul para alterar o "eixo de poder" no mundo. Os responsáveis pela inserção desta concepção na $\mathrm{PEB}$ a partir de 2003 teriam sido o próprio presidente Lula, o primeiro ministro da Casa Civil e o assessor especial para assuntos internacionais. Teria cabido ao então secretário geral do Itamaraty e ao próprio ministro de Relações Exteriores $^{2}$, apenas parcialmente responsáveis pelas grandes linhas da diplomacia de Lula, a tarefa de adequar esta concepção "rudimentar" e até "grosseira", às realidades do poder mundial (Almeida, 2011).

278 O embaixador Rubens Ricupero (2010) considera que em função da atuação do assessor especial para assuntos internacionais teria havido no governo Lula uma "diplomacia paralela" do PT, prejudicial a uma política de Estado que somente é assegurada por meio do Ministério de Relações Exteriores.

O embaixador Rubens Barbosa (2011) menciona em seu livro de memórias que as declarações iniciais de Lula eram favoráveis à continuidade da centralidade das relações com os EUA, mas que ele percebeu um crescimento da atitude antiamericana na política externa por influência do PT e que a ênfase nas relações Sul - Sul colocou a relação com os países desenvolvidos em segundo plano.

O ex-ministro Luz Felipe Lampreia (2010) vai além ao afirmar que a "filiação do Brasil" ao Ocidente dos valores

${ }^{2} \mathrm{O}$ autor se refere respectivamente a José Dirceu, Marco Aurélio Garcia, Samuel Pinheiro Guimarães e Celso Amorim. 
e princípios da democracia, pluralismo político, observância do direito e do respeito aos direitos humanos não seria mais o pensamento dominante no Itamaraty e que as relações com os países da América Latina são influenciadas pelo Foro de São Paulo ${ }^{3}$, impulsionado pelo PT. Além disso, este teria contribuído para a "politização" do debate sobre a Área de Livre Comércio das Américas (Alca).

O termo ideologia, ao pé da letra, significa um conjunto de ideias, pensamentos, doutrinas ou visões de mundo de um indivíduo ou grupo na orientação de suas ações econômicas, sociais, jurídicas, culturais e políticas. Desta forma, doutrinas políticas como democracia, socialismo, conservadorismo, liberalismo, entre outras, representam posições ideológicas e consequentemente qualquer orientação da PEB no governo Lula ou nos anteriores também as representariam. Isso, inclusive, se expressa nas qualificações de diferentes momentos históricos como a "política externa independente", o "pragmatismo responsável”, entre outras, ou então nas orientações rotuladas como "nacionalistas" ou "entreguistas".

Entretanto, há diferentes abordagens do ponto de vista de utilização da ideologia como um instrumento voltado para a geração e manutenção de relações de poder e dominação. Por exemplo, a ideologia na ótica marxista, grosso modo, é um mecanismo aplicado pela burguesia para deformar a realidade e encobrir a exploração dos trabalhadores e a luta de classes.

As críticas dos cinco autores representam uma visão positivista da ideologia que, aliás, tem sido adotada também pela imprensa brasileira, majoritariamente oposta ao governo Lula, e por críticos do governo em outras áreas. A ideologia na ótica positivista significa o desenvolvimento de uma determinada teoria, onde os "sábios e especialistas"

\footnotetext{
${ }^{3}$ Reunião periódica de partidos de esquerda da América Latina ocorrida pela primeira vez em 1990, em São Paulo, no Brasil.
} 
recolhem, sistematizam e organizam ideias para compô-la. A prática decorre da teoria com o intuito de conduzir ao progresso. Por exemplo, a formatação de uma proposta de política de governo para levar um país ao progresso. Assim, a teoria representaria um conjunto de decisões científicas às quais todos deveriam se submeter, mas se há ações que a contradigam teremos situações de anormalidade e desordem, e consequentemente, o progresso estará ameaçado.

Esta narrativa dos ideólogos positivistas distorce o sentido da ideologia a favor do exercício de sua dominação sobre a sociedade, pois eles se colocam como os "técnicos" ou "cientistas" que detêm a razão. Dessa forma, aqueles que se opõem às suas posições, além de equivocarem-se, ameaçam o progresso, agora sim, por meras razões ideológicas de disputa de poder. Dessa forma, a direita se aufere a posição de "dona da verdade", uma vez que suas deliberações seriam "técnicas", e combate as visões de esquerda 280 classificando-as de "ideológicas".

No caso da política externa brasileira, de acordo com os críticos mencionados neste texto, a "teoria” vem sendo consolidada desde a gestão do Barão do Rio Branco frente ao Itamaraty no começo do século XX até o governo FHC, mas as ações adotadas durante o governo Lula representariam "questionamentos" e ameaças à esta teoria consensual e, portanto, também à "ordem e progresso" que ela estabeleceu. A afirmação do ex-ministro Lampreia, mencionada anteriormente, de que o Itamaraty se "desfiliou" do Ocidente, e a descrição apresentada pelo também ex-ministro Ricupero posteriormente no texto sobre as características do presidente Lula em sua atuação internacional, são provavelmente os exemplos mais explícitos do positivismo que norteia grande parte da análise crítica da PEB do governo Lula.

Por sua vez, a afirmação de que política externa é uma política de Estado e não de governo remete à discussão 
sobre o caráter de política pública da PEB em comparação com outras, à legitimidade dos diferentes processos decisórios em política externa e, finalmente, sobre programas partidários relacionados à política externa.

Em primeiro lugar, há convergência quanto à definição de política externa como uma política de responsabilidade do Estado, porém há divergências se este é o ator unitário e mesmo se no interior do aparelho de Estado, o Itamaraty é o ator unitário. Celso Lafer (2009a) defende que a política externa é uma política pública e, consequentemente, de responsabilidade do Estado. No entanto, ele mesmo também argumenta que se trata de uma política pública mais qualitativa do que quantitativa, e para executá-la é preciso sobrepor as demandas da sociedade e as oportunidades e desafios colocados pela conjuntura internacional.

Já para Letícia Pinheiro (2004), a definição de política externa passa pelo conjunto de ações e decisões de um determinado ator, geralmente, mas não exclusivamente, o Estado na relação com outros Estados ou atores não estatais, articulada a partir das demandas domésticas e da situação internacional.

Para Christopher Hill (2003), política externa é a soma das relações externas oficiais conduzidas por um ator independente - usualmente o Estado - nas relações internacionais. No entanto, este autor amplia a abrangência dos atores ao incluir contribuições de diferentes organismos de governo ou de empresas como relações externas "oficiais", uma vez que reconhece como ator o vasto número de transações internacionais conduzidas atualmente.

De acordo com estas afirmações os processos de tomada de decisão sobre política externa lidam com o "doméstico" e o "internacional" e se articulam de modo a definir a projeção do interesse nacional no âmbito das relações internacionais. A dimensão propriamente doméstica das decisões tem origem nas instituições do Estado (Poder Legislativo 
e a burocracia profissionalizada que atua nos ministérios pertinentes, no caso brasileiro o Itamaraty) e na diplomacia presidencial através da persona do próprio presidente da República, no exercício de suas atribuições constitucionais (Milner, 1997; Hudson e Vore, 1995; Gerner, 1995).

Ou seja, o Estado é mais amplo do que um ministério, por mais especializado e capacitado que este seja. Ao incluir outros poderes no processo decisório, particularmente o Legislativo, ele sofre indiretamente a influência de partidos políticos e das forças sociais que estes eventualmente representem.

Dessa forma, é legítimo que um partido político ou uma coalizão de partidos no governo determinem os rumos da política externa de um país, assim como determinam os rumos da economia, das políticas sociais, entre outras políticas públicas. Porém, constata-se que no Brasil, o Poder Legislativo prefere delegar as decisões sobre a 282 política externa para o Poder Executivo o que, no entanto, não significa necessariamente um “consenso", pois esta delegação executada por meio de mera ratificação das decisões se deve mais ao fato que atuar em relação a PEB não traz vantagens em forma de votos ou apoio da opinião pública (Lima e Santos, 2001). Relembrando as campanhas eleitorais presidenciais desde meados dos anos 1990, é notório que os programas partidários no referente à política externa pouco influenciaram os votos do eleitorado, ao contrário de outros países como os EUA, onde este é um fator eleitoral importante.

Mesmo assim, um mapeamento feito pelo historiador Alexandre Fortes sobre os programas eleitorais do PT por ocasião das candidaturas de Lula à presidência da república em 1989, 1994, 1998 e 2002 constata que seguramente foi o candidato com propostas mais abrangentes na área das relações internacionais. Quanto às iniciativas concretas em consideração neste artigo, como a reforma do Con- 
selho de Segurança da ONU e o comércio exterior, ele identifica algumas proposições.

Sobre a reforma da governança global, houve em 1989 uma referência à implantação de uma nova ordem econômica mundial que liquidasse as relações de subordinação e dependência da maior parte dos países em relação aos mais ricos. Em 1994, acrescentou-se uma defesa das reformas nas instituições financeiras internacionais e a democratização da ONU, com a ampliação do Conselho de Segurança, pondo fim ao direito de veto. Já em 1998, simplesmente foi reiterada a necessidade de reforma da governança mundial e, em 2002, foi somente acrescentada a regulação do sistema financeiro internacional.

O tema do comércio internacional começou a ser tratado somente na campanha eleitoral de 1998, quando o programa de Lula propôs a racionalização da abertura comercial com uso de salvaguardas articuladas com uma política industrial e de desenvolvimento tecnológico, e desta forma vincular o comércio exterior ao projeto de desenvolvimento sustentável, porém, sem voltar ao protecionismo cartorial e tampouco aceitar a abertura e casuísmos que favoreceram lobbies próximos ao governo FHC. Em 2002 foi reiterada a vocação multilateral do comércio exterior, bem como a necessidade de diversificar mercados, desconcentrar e diversificar o setor exportador, promover os interesses comerciais do Brasil e remover os obstáculos protecionistas dos países ricos. No continente, a proposta era de combate à Alca, mas aprofundando e aperfeiçoando as relações comerciais bilaterais com os EUA - o mais importante parceiro individual do Brasil no comércio mundial.

Embora o tratamento dado a estes dois temas tenha sido genérico, o fato de abordá-los, assim como a outros não mencionados aqui, como Mercosul, Palestina, direitos humanos etc. é um mérito do PT e também de outros partidos de esquerda no Brasil que têm programa internacional, 
pois em alguma medida contribui para a democratização do debate sobre as relações internacionais no âmbito da sociedade brasileira, bem como coloca visões, pelo menos de uma parte da sociedade, para reflexão dos operadores estatais da política externa.

No aspecto da identidade brasileira que historicamente norteia a PEB e assegura seus elementos de continuidade, como a ausência de conflitos com os países vizinhos e na definição de fronteiras, seu caráter universalista, o apreço ao direito internacional, entre outros (Lafer, 2009a), não houve mudanças nesta avaliação conceitual conforme pode ser constatado na prática e em textos de Samuel Pinheiro Guimarães (2010) e Celso Amorim (2011).

Salvo as divergências que marcam a trajetória das relações entre Brasil e Estados Unidos desde seu início histórico, não houve abalos significativos (Garcia, 2010). Guimarães (2010) chama a atenção para o crescimento do comér284 cio entre os dois países, inclusive das importações brasileiras, bem como para a estabilidade dos investimentos americanos no Brasil. Poderíamos acrescentar o intercâmbio de visitas presidenciais de Lula e Bush, além do recém-criado grupo de trabalho para estudar a possibilidade de eliminação de vistos como comprovante que não existe nem crise nas relações bilaterais e nem uma postura antiamericana do PT ou do governo Lula.

Por fim, a crítica das relações com países governados por ditaduras é uma tentativa sutil de identificar o PT e Lula com regimes autoritários. Um dos princípios tradicionais do consenso da PEB é a não ingerência em assuntos internos de outros países. Portanto, a escolha das relações se dá independentemente do tipo de regime em vigor em cada país e é definida pragmaticamente a partir dos interesses brasileiros, o que, evidentemente, não exime o governo de promover o respeito aos direitos humanos em todos os fóruns. 
Porém, se nossas relações fossem apenas com países de regimes democráticos e plenamente respeitadores dos direitos humanos, o Brasil nunca deveria ter estabelecido relações com a China, Arábia Saudita, Indonésia, Egito, Iraque, entre outros com os quais nos relacionamos e comerciamos há muitos anos, inclusive exportando armas para alguns deles.

Por fim, se isso fosse uma condição sinequa non para manter relações diplomáticas, como explicar então que tantos profissionais da política externa adeptos da democracia ocidental tenham servido ao Estado governado por sucessivos generais no Brasil entre 1964 e 1985?

\section{A reforma do Conselho de Segurança da ONU}

As críticas em relação a este tema partem de Almeida (2011) e Lampreia (2010). O primeiro identifica que a conquista de uma cadeira permanente no Conselho de Segurança nas Nações Unidas nunca fez parte da agenda externa do PT, mas que Lula foi persuadido a assumir esta causa pelos diplomatas profissionais. A campanha que ele empreendeu desde então teria provocado desgastes com parceiros latino-americanos como Colômbia, México e principalmente a Argentina. Uma atitude contrária à do presidente Fernando Henrique Cardoso, que teria percebido que isso poderia ocorrer e que de qualquer maneira os cinco membros permanentes ainda não estariam convencidos da necessidade da reforma. A busca desta durante o governo Lula também teria acarretado custos por meio de "generosos" cancelamentos de dívidas de países latino-americanos e africanos, da cooperação oferecida aos mesmos e outros países destes continentes e da abertura de dezenas de novos postos diplomáticos em quase todos os países do Sul (Almeida, 2011). No entanto, Lampreia (2010) admite que o governo ao qual serviu como ministro era favorável à reforma da ONU e que inclusive atuou com a Alemanha, Índia e Japão (G-4) com esta finalidade, porém sem enfatizar a questão 
da cadeira permanente. Contudo, o governo Lula teria adotado a busca da cadeira permanente como um "norte" da PEB transformando-o em um esforço fracassado.

O tema não é novo. O governo brasileiro retirou-se da Liga das Nações em 1926 porque o assento que ocupou durante seis anos seguidos foi cedido para a Alemanha. Eugenio Vargas Garcia (2012) registra que o presidente Franklin D. Roosevelt dos EUA era favorável à inclusão do Brasil como membro permanente do Conselho de Segurança quando a conformação da ONU começou a ser debatida em 1944, mas que a proposta sofreu oposição do Reino Unido e da União Soviética, pois estes consideravam que representaria um "voto duplo" dos Estados Unidos. O governo brasileiro ainda tentou que a assembleia de fundação da organização em 1945 aprovasse um prazo para revisão das suas normas de funcionamento, o que não ocorreu, mas o Brasil assumiu uma vaga temporária pela primeira vez em 1946.

286 Depois do presidente Getúlio Vargas, o primeiro a retomar o tema foi o presidente Sarney no discurso de abertura da Assembleia Geral em 1989. Posteriormente, o governo Itamar Franco relançou a candidatura brasileira ao assento permanente no bojo de uma reforma necessária da instituição, proposta mantida pelos seus sucessores e com maior ênfase a partir de 2003 (Haag, 2012).

No entanto, apesar de a face mais visível da reforma do sistema internacional ser o rompimento do monopólio da governança pelas grandes potências (algumas não tão grandes assim na atualidade) e a redistribuição dos cargos de mando, a posição do governo Lula sempre enfatizou a necessidade de democratizá-lo e adequá-lo à conjuntura atual, pois a fundação da ONU se deu no contexto do final da Segunda Guerra Mundial com a participação de menos de 50 países independentes, o que contrasta com a globalização e a existência de 197 membros filiados à organização nos dias de hoje. Não resta dúvida que o sistema está esgarçado atualmente, pois além de 
não conseguir abrigar os interesses legítimos de um grande número de países, também não consegue contemplar os interesses da sociedade em temas que lhe diz respeito diretamente, como meio ambiente, direitos humanos e outros.

Guardadas as proporções e as funções institucionais, o mesmo raciocínio se aplicaria também a outras organizações como, por exemplo, as instituições de Bretton Woods - Fundo Monetário Internacional (FMI) e Banco Mundial cuja atuação é hegemonizada pelos EUA e União Europeia.

O esforço da PEB a partir de 2003 tem sido neste sentido e representa uma posição proativa importante apesar dos obstáculos conhecidos, pois aguardar a singela sensibilização dos detentores do poder para dividi-lo sem, no mínimo, questionar o desequilíbrio da atual governança global, representaria um conformismo irresponsável e a perpetuação de uma situação inaceitável.

As iniciativas adotadas pelo governo Lula nesta direção nada mais foram do que uma maneira de reafirmar princípios da PEB desde que Rui Barbosa defendeu a existência da "igualdade entre os Estados" na Conferência de Haia em 1907 ou quando o governo brasileiro participou das negociações do Tratado de Versalhes em 1919 defendendo seus "interesses gerais" (Lafer, 2000). Porém, o governo Lula também procurou assumir responsabilidades, voluntariamente, como a participação na missão de paz no Haiti, a promoção de ajuda humanitária e a busca de alternativas a conflitos como a invasão americana do Iraque ou a questão nuclear do Irã.

Entretanto, as iniciativas não se aplicaram apenas aos temas ligados ao Conselho de Segurança da ONU, mas também a outros, como a criação do G-20 financeiro e as medidas para redistribuir minimamente o controle do FMI e do Banco Mundial, bem como para mudar a agenda de negociações da Organização Mundial de Comércio (OMC).

Ricupero (2010), crítico da política externa de Lula, inclusive, reconheceu o esforço junto ao G-20 para melhorar 
o equilíbrio da governança das instituições financeiras internacionais como importante e que a discussão sobre a reforma da ONU coloca o Brasil em posição vantajosa quando chegar o momento da reforma do Conselho de Segurança.

\section{0 comércio exterior}

As críticas nesta área referem-se à excessiva concentração de esforços nas negociações da OMC sem que houvesse possibilidades menos ambiciosas diante das dificuldades da conclusão de uma nova rodada (Ricupero, 2010), bem como o abandono de alternativas como a Alca (Almeida, 2011 e Lampreia, 2010).

Neste tema não há muita coincidência nas críticas, pois Ricupero e Barbosa reconhecem o desequilíbrio embutido nas negociações da Alca. O embaixador Rubens Barbosa (2011) inclusive dizia que se as negociações não se equilibrassem, seria melhor encerrá-las como acabou 288 ocorrendo. Lampreia (2010) quando era ministro reiterou diversas vezes a ideia de que se o Mercosul era um destino, a Alca seria uma opção, embora tenha responsabilizado a "politização" do tema pela impossibilidade do governo Lula de avançar nas negociações.

A rigor, com poucas exceções, a diplomacia brasileira sempre tratou as negociações da Alca com reservas quanto à possibilidade de atingir um acordo equilibrado diante dos efeitos ainda vigentes da onda de liberalização acarretada pela rodada Uruguai do GATT entre os anos de 1986 e 1994. Porém, o governo Lula não se recusou a ocupar a copresidência das negociações da Alca com o governo americano e sua proposta de negociação em "três trilhos" ${ }^{4}$ foi em princípio aceita pelos Estados Unidos como uma alter-

\footnotetext{
${ }^{4}$ Essa proposta dividia a agenda em três partes: temas que seriam negociados no âmbito dos 34 países da Alca, temas que poderiam ser objeto de um acordo plurilateral e temas que deveriam ser remetidos para discussão na OMC.
} 
nativa, mas rejeitada por outros governos como os do México, Chile e Canadá, o que interrompeu definitivamente as negociações (Amorim, 2011; Barbosa, 2011).

A rodada Doha sofreu um impasse na conferência ministerial de Cancun em 2003 quando o G-20 foi articulado com participação decisiva do governo brasileiro para fortalecer a posição dos países em desenvolvimento nas negociações agrícolas. Porém, o impasse na rodada surgiu diante da recusa de muitos países, principalmente os de menor desenvolvimento relativo, em seguir adiante com a negociação dos chamados "temas de cingapura" - investimentos, compras governamentais, propriedade intelectual, meio ambiente, entre outros (Jakobsen, 2005).

No ano seguinte aconteceu uma reunião entre o "quadrilátero” (EUA, União Europeia, Japão e Canadá), Brasil e Índia representando o G-20 e Austrália representando o Grupo de Cairns. A reunião tinha como objetivo redefinir a agenda da rodada Doha e resumiu as negociações em torno de quatro temas: bens não agrícolas (Nama), agricultura, serviços e facilitação de comércio. Isso impulsionou as negociações novamente e o governo brasileiro chegou a aceitar uma proposta de acordo em 2008, que não vingou por divergências de outros membros do G-20, particularmente, a Índia. Até hoje elas não foram concluídas e não se pode culpar a PEB de Lula por isso.

Aliás, tanto na OMC, como na retomada de negociações em vários fóruns internacionais, o governo Lula foi um dos mais ardorosos defensores da pauta explícita de romper os subsídios agrícolas praticados pelos países desenvolvidos, com a preocupação implícita de preservar o sistema multilateral de comércio, apesar dos óbices de várias organizações sociais no Brasil de levar as negociações da rodada Doha adiante.

O esforço do governo para estabelecer novas relações internacionais no eixo do Sul também gerou resultados 
positivos no comércio do Brasil com a América do Sul, África, países Árabes e China, que em 2009 respondiam por $50 \%$ do comércio externo brasileiro (ICTSD, 2009).

A participação brasileira no comércio mundial cresceu a partir de 2003 e com significativos superávits, mas em 2007 iniciou-se a crise econômica que assola os países centrais, e que até hoje não tem perspectivas de solução no curto prazo. A história comprova que é durante as crises que o protecionismo comercial se fortalece, dificultando enormemente a viabilização do livre comércio, e é isso o que está acontecendo agora. Além disso, nesta última década não se registra nenhum acordo comercial relevante, seja multilateral ou plurilateral.

\section{A diplomacia presidencial}

Este tema é levantado em artigo específico de autoria do embaixador Rubens Ricupero (2010) que julga ter havido 290 excesso de protagonismo presidencial na política externa durante o governo Lula, e que este teria prejudicado o desenvolvimento da mesma enquanto uma política de Estado, causando danos às relações com outros parceiros e favorecendo a influência partidária sobre a PEB. Ele chegou a comparar seu desempenho à política personalista do presidente francês Charles de Gaulle.

No entanto, do ponto de vista do processo decisório em política externa, a diplomacia presidencial é muito importante em vários países de regime presidencialista como, por exemplo, nos Estados Unidos, onde o papel do presidente é determinante nas declarações de guerra e paz, na proposição de tratados internacionais, entre outras decisões, mesmo quando tem que submetê-las à aprovação do Poder Legislativo. No caso de regimes parlamentaristas, é comum que o presidente exerça o papel de representação internacional do país, sendo às vezes a sua única função. 
Porém, o autor menciona uma série de características inerentes ao desempenho diplomático de Lula que seriam negativas, como "personalismo, carisma, nacionalismo, populismo, questionamento do poder preponderante no mundo, busca de influência exclusiva, crítico não-consensual, pouco sensível a ideias e valores morais dos temas clássicos em relações internacionais”, entre outras (Ricupero, 2010).

A impressão é que o problema real reside de fato na consideração de quem estaria mais apto e deveria conduzir a PEB na opinião do autor, pois estas características não representam necessariamente defeitos e seria difícil identificar quais danos teriam causado. Há, no entanto, uma frase de autoria do ex-presidente Tancredo Noves no texto de Ricupero que é muito ilustrativa: “[...] se há um ponto na política brasileira que encontrou consenso em todas as correntes de pensamento, esse ponto é a política externa levada a efeito pelo Itamaraty" (apud Ricupero, 2010).

De acordo com o autor, o presidente Fernando Henrique, sim, é que ajudava na condução da política externa, em função de ser um intelectual reconhecido internacionalmente, e também pelas suas relações de amizade com o presidente Clinton dos EUA e o primeiro ministro Toni Blair do Reino Unido. Com isso, fica registrado o papel que o autor julga ser adequado para um presidente realizar na política externa. Porém, colocado desta forma, isso representa uma visão distorcida do papel presidencial na execução de políticas de Estado, pois em um regime presidencialista como o brasileiro são os ministérios que devem ajudar o presidente a governar, além de executar suas determinações, e não o contrário, embora um trabalho harmonioso entre a diplomacia presidencial e o ministério de relações exteriores seja amplamente desejável.

$\mathrm{O}$ autor, portanto, também reforça a ideia de que a burocracia especializada do ministério das relações exte- 
riores seria a instituição mais capacitada e equilibrada para tomar as decisões que interessam ao país. Tal discurso pode explicar como o Itamaraty, ao longo de sua existência, se insulou do conjunto do Estado (Cheibub, 1985), a ponto de no tocante à PEB se colocar, no mínimo, no mesmo patamar de poder do presidente da República, seja quando o orienta ou quando dá formato às posições presidenciais, mesmo elas sendo "equivocadas" na opinião de alguns diplomatas (Almeida, 2011).

Ricupero também critica a assessoria internacional do presidente, uma escolha do mandatário que recaiu sobre o ex-secretário de relações internacionais do PT, um professor universitário que acumulou experiência em política externa em sua função partidária e nos anos em que viveu no exílio. Neste caso, como se trata de um cargo de confiança, a diferença quanto à escolha, em comparação com os assessores dos presidentes que antecederam Lula, é sua

292 origem acadêmica e não diplomática, o que pode ser visto de forma apenas positiva se considerada a ótica de diversificação da influência da política doméstica na PEB e redução do monopólio da burocracia especializada do Itamaraty.

Por outro lado, a preocupação com o envolvimento partidário da diplomacia brasileira é sem sentido, pois dos 34 ministros de relações exteriores que ocuparam o cargo entre 1912 e 2000, 14 eram diplomatas de carreira ou profissionais liberais e 20 eram políticos, de onde se supõe, portanto, que tivessem filiação partidária (Barreto, 2001). O Barão do Rio Branco e o ex-presidente Fernando Henrique Cardoso, que foi chanceler de 1992 a 1993, certamente tinham.

\section{$* * *$}

Os argumentos analisados se fragilizam porque lidam com algumas medidas na política externa que tiveram origem em governos anteriores ao de Lula e, portanto, também a 
participação dos críticos em questão, de maneira que não se justifica a atemporalidade das críticas.

No entanto, apesar disso, deduz-se que há três diferenças fundamentais entre a $\mathrm{PEB}$ que os autores em tela consideram correta e a política externa levada adiante pelo governo Lula, considerada pelos autores como equivocada, para dizer o mínimo.

A primeira é a análise sistêmica diferenciada, particularmente, do papel que caberia a uma potência média como o Brasil. Na opinião dos críticos, cabe-lhe espaço e defesa de "interesses gerais" em consonância com o poder dominante representado pelas grandes potências como os EUA, União Europeia e Japão, que no mundo globalizado determinam os rumos da economia, bem como a conformação das cadeias produtivas mundiais. Porém, na opinião dos formuladores da PEB atual, o Brasil é uma potência média que deverá resolver suas disparidades internas e buscar lugar entre os grandes (Guimarães, 2005; Garcia, 2010).

A segunda, esta sim, é ideológica e partidária: é perceptível nos textos a preferência dos autores pelos governos que serviram após a redemocratização do Brasil, principalmente o de Fernando Henrique Cardoso, em detrimento do governo Lula, entre outros motivos, por este ter prestigiado outros diplomatas de carreira nos cargos de confiança dentro do Itamaraty.

Esta segunda diferença relaciona-se com a terceira, pois é consensual entre os cinco autores a preponderância do Itamaraty insulado como principal responsável pela operacionalização da PEB. Na contramão disso, o governo Lula teria aberto o precedente de contratar um assessor de assuntos internacionais que não advém do quadro diplomático, além de tomar para si um papel na execução da política externa que não lhe caberia ou que teria sido inadequado. Entretanto, o prestígio internacional adquirido por Lula ao longo de seus oito anos de governo contradiz esta percepção. 
A terceira diferença também representa o paradoxo de que durante o governo Lula o Itamaraty manteve, como sempre, o controle da gestão da PEB, tendo inclusive se fortalecido estruturalmente. A diferença, porém, está na hegemonia da condução da política externa no ministério, que mudou para as mãos dos setores nacionalistas e desenvolvimentistas.

\section{KJELD AAGAARD JAKOBSEN}

é doutorando em Relações Internacionais pela USP.

\section{Referências bibliográficas}

ALMEIDA, P. R. 2011. "A diplomacia da era Lula: balanço e avaliação". Revista Política Externa, v. 20, n. 3, pp. 95-114.

AMORIM, C. 2011. Conversas com jovens diplomatas. São Paulo: Benvirá.

BARBOSA, R. 2011. O Dissenso de Washington: notas de um observador privilegiado sobre as relações Brasil - Estados Unidos. Rio de Janeiro: Agir.

BARRETO, F. M. 2001. Os sucessores do Barão 1912 - 1964: relações exteriores do Brasil. São Paulo: Paz e Terra.

294 CHEIBUB, Zairo. 1985. "Diplomacia e construção institucional: o Itamaraty em perspectiva histórica”. Dados - Revista de Ciências Sociais, v. 28, n. 1, pp. 113-31.

GARCIA, E. V. 2012. O sexto membro permanente: o Brasil e a criação da ONU. Rio de Janeiro: Contraponto.

GARCIA, M. A. 2010. “A política externa”. In: JAKOBSEN, K. (org). A nova política externa. São Paulo: Editora Fundação Perseu Abramo.

GERNER, D. J. 1995. "The evolution of the study of foreign policy". In: NEACK, L. et al. (orgs.). Foreign policy analysis: continuity and change in its second generation. New Jersey: Prentice-Hall, Inc.

GUIMARÃES, S. P. 2005. Desafios brasileiros na era dos gigantes. Rio de Janeiro: Contraponto.

2010. "Uma política externa para enfrentar as vulnerabilidades e disparidades”. In: JAKOBSEN, K. (org). A nova política externa. São Paulo: Editora Fundação Perseu Abramo.

HAAG, C. 2012. "A dança das cadeiras na ONU”. Revista Pesquisa Fapesp, n. 197, pp. 78-81.

HILL, C. 2003. The changing politics of foreign policy. New York: Palgrave Macmillan.

HUDSON, V.; VORE, C. S. 1995. "Foreign policy analysis, yesterday, 
today and tomorrow”. Mershon International Studies Review, v. 39, n. 2, pp. 209-38.

ICTSD. 2009. Relatório Pontes da International Centre for Trade and Sustainable Development. Disponível em http://ictsd.org/news/ pontes $/$ ?volume=5\&number=2. Acesso em 10/07/2013.

JAKOBSEN, K. 2005. Comércio internacional e desenvolvimento: do GATT a OMC - discurso e prática. São Paulo: Editora Fundação Perseu Abramo.

LAFER, C. 2000. "Brazilian international identity and foreign policy: past, present and future". Daedalus, v. 129, n. 2, pp. 207-38. . 2009a. A identidade internacional do Brasil e a politica externa brasileira: passado, presente e futuro. São Paulo: Editora Perspectiva S.A.. . 2009b. "Partidarização da política externa". O Estado de S. Paulo, 20/12.

LAMPREIA, L. F. 2010. O Brasil e os ventos do mundo: memórias de cinco décadas na cena internacional. Rio de Janeiro: Objetiva.

LIMA, M. R. S.; SANTOS, F. 2001. "O congresso e a política de comércio exterior”. Lua Nova, n. 52, pp. 129-49.

MILNER, H. V. 1997. Interests, institutions and information. Princeton: Princeton University Press.

PINHEIRO, L. 2004. Politica externa brasileira: 1889 - 2002. Rio de Janeiro: Jorge Zahar.

RICUPERO, R. 2010. À sombra de Charles de Gaulle: uma diplomacia carismática e intransferível. Novos Estudos - Cebrap, n. 87, pp. 35-58. 


\title{
DESVENTURAS DE ALGUNS CRÍTICOS DA POLÍTICA EXTERNA DO GOVERNO LULA
}

\author{
KJELD AAGAARD JAKOBSEN
}

Resumo: O presente artigo busca analisar algumas críticas de especialistas brasileiros à política externa dos dois mandatos do governo Lula, em particular quanto à coerência e fundamentação dos argumentos utilizados pelos autores. A constatação é que as críticas se baseiam em uma análise sistêmica particular, bem como na convicção de que a burocracia de Estado é o ator unitário na definição e operacionalização da Política Externa Brasileira (PEB).

Palavras chave: Política Externa; Partido; Presidente; Ideologia.

\section{MISADVENTURES OF SOME CRITICS OF THE FOREIGN POLICY OF LULA'S GOVERNIMENT}

Abstract: This article aims to analyze some criticisms of Brazilian specialists to Lula's governments' foreign affairs policy, particularly, their fundaments and coherence. The finding is that they are grounded in a particular systemic analysis, as well as the conviction that the State bureaucracy is the single actor responsible for the definition and operation of the Brazilian foreign affairs policy.

Keywords: Foreign Policy; Party; President; Ideology. 